Diagnostics (Not pharmaceutical, diagnostics company), Cem Gabay Grant/research support from: Roche, Pfizer, AB2 Bio Ltd, Consultant for: Roche, Pfizer, Lilly, AbbVie, Sanofi, Regeneron, Bristol-Myers Squibb, Novartis, UCB, AB2 Bio Ltd, Debiopharm DOI: 10.1136/annrheumdis-2019-eular.2035

\section{AB0275 RHEUMATOID ARTHRITIS IN HISPANIC PATIENTS: DEMOGRAPHIC AND BASELINE CLINICAL CHARACTERISTICS IN AN EARLY REFERRAL COHORT IN MEXICO VERSUS ROUTINE CARE IN THE UNITED STATES}

Elena Obreja ${ }^{1}$, Virginia Dr. Pascual ${ }^{2}$, Mariam Riad $^{1}$, Irazú Contreras-Yáñez ${ }^{2}$, Isabel Castrejon ${ }^{1} .{ }^{1}$ Rush University Medical Center, Rheumatology, Chicago, United States of America; ${ }^{2}$ National Institute Salvador Zubiran, Immunology and Rheumatology, Mexico, Mexico

Background: Hispanics are the largest minority group in the United States (US) and his percentage is expected to increase $(28.6 \% \text { by } 2060)^{1}$, being Mexicans the largest group (67.9\%). RA patients from Latin-America have distinctive features from White patients. The literature highlights a younger age at presentation and a different clinical expression compared with White ${ }^{2}$ but few data for Hispanic patients in US are available.

Objectives: We compared baseline demographic, clinical features and disease management among Hispanic RA patients from two well characterized cohorts, in the USA and Mexico city.

Methods: An early arthritis clinic (EAC) was established at Site 1 (Mexico City); patients with recent-onset RA ( $<1$ year of symptoms) had a standardized assessment and received "treat to target" treatment. At Site 2 (US), a "routine care" cohort was initiated in 2011, and all patients completed a multidimensional health assessment questionnaire (MDHAQ) as part of their routine care. Patients from both sites had baseline complete evaluation including sociodemographic data, patient-reported outcomes (PROs) (patient global assessment, pain-VAS, HAQ/MHAQ, RAPID3), laboratory data, and tender joint counts. Initial treatment was noted. Data from both sites were compared and appropriate statistics was used.

Results: 201 patients from site 1 and 179 from site 2 were included (table 1); among them, $105(52 \%)$ and 37 (19\%), respectively, were DMARDs-naïve at baseline. Patients from site 2 were older and had longer disease duration, however demographic characteristics did not differ. Naïve-DMARDs patients from site 2 scored significantly higher pain-VAS and tender joint counts, and had higher ESR values ( $\leq \leq 0.05$, Mann Withney); a similar tendency was seen for other PROs. Time to DMARDs initiation was shorter in the EAC.

Table.. Demographic and clinical characteristics at first rheumatology visit for RA patients. All data as median (IQR) unless otherwise indicated. ${ }^{*} p \leq 0.003$. NA, not applicable

\begin{tabular}{|c|c|c|c|c|}
\hline & \multicolumn{2}{|c|}{$\begin{array}{l}\text { Site 1: Mexico-Early } \\
\text { Arthritis Clinic }\end{array}$} & \multicolumn{2}{|c|}{$\begin{array}{l}\text { Site 2: US-RA Routine } \\
\text { Care }\end{array}$} \\
\hline & $\begin{array}{l}\text { Patients on } \\
\text { DMARD } \\
\mathrm{N}=96\end{array}$ & $\begin{array}{c}\text { DMARD } \\
\text { Naïve } \\
\mathrm{N}=105\end{array}$ & $\begin{array}{c}\text { Patients on } \\
\text { DMARD } \\
\mathrm{N}=142\end{array}$ & $\begin{array}{c}\text { DMARD } \\
\text { Naïve } \\
\text { N=37 }\end{array}$ \\
\hline \multicolumn{5}{|l|}{ DEMOGRAPHICS } \\
\hline Age, years, mean (SD) & $38.6(13)$ & $\begin{array}{c}38.8 \\
(12.9)\end{array}$ & $55.7(15.4)$ & $\begin{array}{c}45.5 \\
(12.6)\end{array}$ \\
\hline Female, $\%$ & $87.5 \%$ & $93 \%$ & $87 \%$ & $83 \%$ \\
\hline Yrs of formal education & $12(9,16)$ & $12(9,14)$ & $12(9,14)$ & $\begin{array}{c}12(9.5 \\
14)\end{array}$ \\
\hline Symptom duration-first visit, mo & $5.6(3.9,7.9)$ & $\begin{array}{c}4.7(2.9 \\
6.5)\end{array}$ & NA & $\begin{array}{c}22.7(3.0, \\
47.9)\end{array}$ \\
\hline$\%$ treated as early $R A(<6 m)$ & 59.4 & 70 & NA & 34 \\
\hline \multicolumn{5}{|l|}{ PROs } \\
\hline Pain $(0-10)$ & $4.2(2.4,6)$ & $\begin{array}{c}6.2(3.8 \\
7.8)\end{array}$ & $6(2.7,8)$ & $8(6,8.5)$ \\
\hline Patient global assessment $(0-10)$ & $4.4(2.3,6.8)$ & $\begin{array}{c}6.7(3.9- \\
8.2)\end{array}$ & $5.5(2.5,8)$ & $\begin{array}{l}7.5(4, \\
8.5)\end{array}$ \\
\hline $\begin{array}{l}\text { Tender Joint Counts (TJC28 or self- } \\
\text { reported RADAI48) }\end{array}$ & $11(6,18)$ & $14(9,20)$ & $12(3,24)$ & $20(7,32)$ \\
\hline RAPID3 (0-30) & $\begin{array}{c}11.0 \\
(6.8-16.3)\end{array}$ & $\begin{array}{c}15.5 \\
(10.3- \\
19.1)\end{array}$ & $\begin{array}{c}13.6 \\
(6,20)\end{array}$ & $\begin{array}{c}15.3 \\
(10,21.5)\end{array}$ \\
\hline Physical Function-MHAQ (0-10) & $2.2(1-4)$ & $\begin{array}{c}3(1.3- \\
4.3)\end{array}$ & $3.0(0.6,4.2)$ & $\begin{array}{c}2.4(1.2 \\
4.8)\end{array}$ \\
\hline \multicolumn{5}{|l|}{ SEROLOGIC DATA } \\
\hline $\mathrm{RF}, \%$ & 82 & 82 & 75 & 72 \\
\hline ACPA, $\%$ & 84 & 86 & 67 & 81 \\
\hline $\mathrm{ESR}, \mathrm{mm} / \mathrm{hr}$ & $21.5(11,48)$ & $\begin{array}{c}23(12.5 \\
38)\end{array}$ & NA & $\begin{array}{c}35.5(14 \\
55)\end{array}$ \\
\hline
\end{tabular}

\begin{tabular}{lcccc} 
CRP, mg/dl & 0.68 & 0.67 & NA & 0.69 \\
& $(0.22,2.22)$ & $(0.27$, & & $(0.54$, \\
& & $2.48)$ & & $1.23)$ \\
TREATMENT & & & & \\
MTX,\% & 89 & 93 & NA & $63^{*}$ \\
Other DMARDs,\% & 59 & 66 & NA & $44^{*}$ \\
Prednisone,\% & 47 & 59 & NA & $80^{*}$ \\
Mean dose (SD), mg & $7.5(2.3)$ & $7.7(3.5)$ & & $9.3(3.4)$ \\
Time to initiate DMARD, mo & NA & $0.2(0-$ & NA & $0.7(0.4$, \\
& & $0.4)$ & & $1.4)^{*}$ \\
\hline
\end{tabular}

Conclusion: Hispanic patients with RA from different regions in America may differ in their initial presentation. Naïve DMARDs patients belonging to an early RA cohort had shorter presentation to rheumatology resulting in earlier treatment initiation, which has been associated to better outcomes. EACs facilitate the identification of patients with recent-onset disease and help provide early access to effective therapies.

\section{REFERENCES}

[1] Public Health Reviews 2016; 37:31.

[2] Best Pract Clin Rheumatol 2008; 22:621-41.

Disclosure of Interests: None declared

DOI: 10.1136/annrheumdis-2019-eular.980

\section{AB0276 IS PREDICTION OF CLINICAL RESPONSE TO METHOTREXATE IN INDIVIDUAL RHEUMATOID ARTHRITIS PATIENTS POSSIBLE? RESULTS OF A SYSTEMATIC LITERATURE REVIEW}

Nadia M. T. Roodenrijs, Marlies van der Goes, Paco Welsing, Janneke Tekstra Jacob M. van Laar, Floris Lafeber, Johannes Wj Bijlsma, Johannes W. G. Jacobs. University Medical Center Utrecht, Rheumatology and Clinical Immunology, Utrecht, Netherlands

Objectives: To identify, by a systematic literature review, predictors of clinical response to methotrexate (MTX) treatment in rheumatoid arthritis (RA) patients, which would facilitate personalised treatment.

Methods: PubMed and Embase databases were searched for original articles. Additionally, congress abstracts of European League Against Rheumatism (EULAR) and American College of Rheumatology (ACR) annual meetings of the past 2 years were screened. Articles describing baseline predictors of clinical response to MTX after 3 to 6 months were included since this reflects the time span used to determine treatment effectiveness and decide on treatment changes in treat-to-target recommendations.

Results: 30 articles were included, containing 100 different predictors and 11 predictive models, but only 19 predictors and 2 predictive models were studied in multiple similar RA cohorts. Of these 19 predictors, 4 were described in multiple articles sharing details on statistical analyses and response outcomes, allowing pooling of the predictive values of these 4 factors (Figure 1). Conflicting non-statistically significant associations between age and response were found (Figure 1a)..$^{1-4}$ Female gender was found to be a predictor of non-response in two studies (OR (odds ratio) 0.55 and 0.54), but these findings could not be replicated in two other studies (Figure 1b). ${ }^{1-4}$ In two studies, smoking predicted non-response (adjusted OR 0.35 and 0.60 ), but this was inconsistent over all response criteria assessed (Figure 1c). ${ }^{3,5}$ Higher disease activity score was a predictor of response in two studies (adjusted OR 1.12 and 2.7), conflicting and non-statistically significant predictive values were found in two other studies (Figure 1d). ${ }^{2-4,6}$ Rheumatoid factor positivity predicted non-response in two studies (adjusted hazard ratio 0.61, adjusted OR 0.4), although this was not found in three other studies. ${ }^{2-4,7,8}$ Heterogeneity between studies prohibited pooling of predictive values. Additionally, a validated epigenetic model was found: area under the receiver operating characteristic curve 0.90 in the development cohort and 0.91 in a validation cohort. $^{9}$

Conclusion: No predictors were identified reliably predicting clinical response to MTX after 3 to 6 months in the individual patient: clinical predictors were weak. However, a promising epigenetic model was found that needs further validation. Future studies on prediction of response to MTX should focus on combining clinical characteristics with genetic and other laboratory biomarkers and on predicting outcome after 3 to 6 months of treatment, to get closer to personalised medicine.

\section{REFERENCES}

[1] Kavanaugh, et al. Ann Rheum Dis 2017;76:822-3. 
[2] Ponchel, et al. Ann Rheum Dis 2014;73:2047-53.

[3] Saevarsdottir, et al. Ann Rheum Dis 2011;70:469-75.

[4] Wessels, et al. Arthritis Rheum 2006;54:2830-9.

[5] Saevarsdottir, et al. Arthritis Rheum 2011;63:26-36.

[6] Tan, et al. Int J Rheum Dis 2016;19:482-9.

[7] Bugatti, et al. Ann Rheum Dis 2017;76:790-1.

[8] Stühlmuller, et al. Clin Immunol 2016;171:50-61.

[9] Carini, et al. J Transl Med 2018;16:1-11.

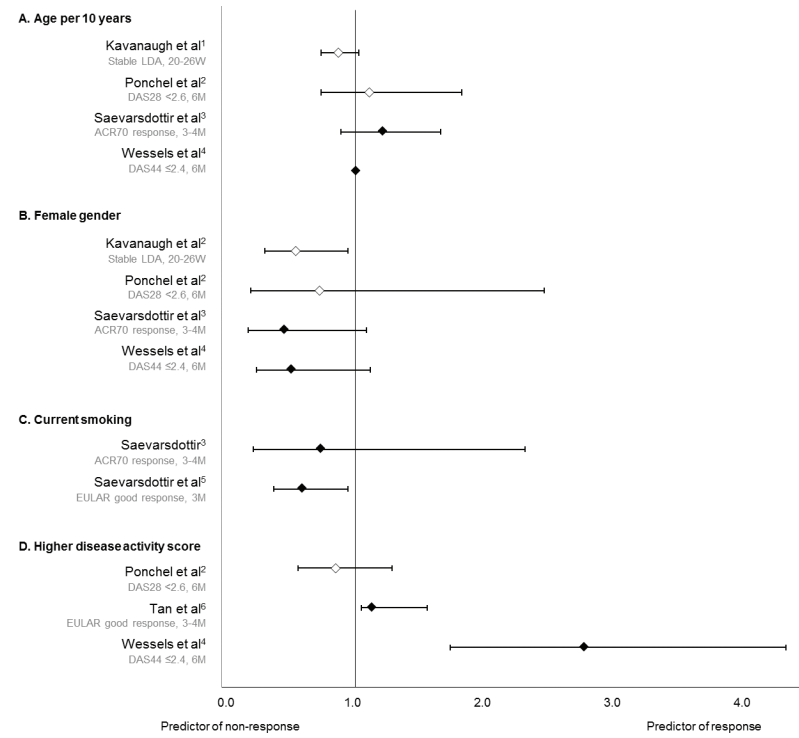

Figure 1. Associations between baseline predictors and response to MTX according to different outcome criteria and at different time points, in odds ratios with $95 \%$ confidence interval.

Odds ratios are shown as diamonds: White diamonds represent univariate analyses; black diamonds multivariate analyses; and whiskers $95 \%$ confidence intervals. Used response criteria and time points of clinical response are shown in grey type for each study. DAS28: disease activity score assessing 28 joints; DAS44: disease activity score assessing 44 joints; LDA: low disease activity (definition not specified in article); M: months; W: weeks.

Disclosure of Interests: Nadia M. T. Roodenrijs: None declared, Marlies van der Goes: None declared, Paco Welsing: None declared, Janneke Tekstra: None declared, Jacob M. van Laar Grant/research support from: Genentech, Consultant for: F. Hoffmann-La Roche, Floris Lafeber Shareholder of: ArthroSave, Grant/research support from: FOREUM; Dutch Arthritis Society, Johannes WJ Bijlsma Grant/research support from: The department of the author who included patients (JWJB) in the U-Act-Early trial received reimbursements from Roche Nederland BV. JWJB reported grants and fees from Roche, AbbVie, Bristol-Myers Squibb, Merck Sharp \& Dohme, Pfizer, and UCB

University Medical Center Utrecht, Utrecht University, Consultant for: SUN Pharma, Speakers bureau: Lilly, Roche, Johannes W. G. Jacobs Grant/ research support from: Roche, Consultant for: Roche

DOI: 10.1136/annrheumdis-2019-eular.4176

\section{AB0277 EFFECT OF DISEASE DURATION AND OTHER PATIENT BASELINE CHARACTERISTICS ON OUTCOMES IN TOCILIZUMAB-TREATED RHEUMATOID ARTHRITIS PATIENTS: A POOLED ANALYSIS}

Andrea Rubbert-Roth ${ }^{1}$, Daniel Aletaha ${ }^{2}$, Jenny Devenport ${ }^{3}$, Paris N. Sidiropoulos ${ }^{3}$, Yves Luder ${ }^{4}$, Michael Edwardes ${ }^{5}$, Johannes W. G. Jacobs ${ }^{6} .{ }^{1}$ Kantonsspital $S t$ Gallen, St Gallen, Switzerland; ${ }^{2}$ Medical University of Vienna, Vienna, Austria; ${ }^{3}$ Genentech, South San Francisco, United States of America; ${ }^{4} \mathrm{~F}$ Hoffmann-La Roche, Basel, Switzerland; ${ }^{5}$ Everest Clinical Research, Markham, Canada; ${ }^{6}$ University Medical Center, Utrecht, Netherlands

Background: Tocilizumab (TCZ) efficacy and safety in rheumatoid arthritis (RA) have been well established by numerous phase 3 and 4 studies and observational studies.

Objectives: To explore the extent to which disease duration, inflammation, disease burden, and other baseline factors explain variations in outcomes in studies of RA patients treated with TCZ.

Methods: This was a pooled analysis of methotrexate-inadequate responding (IR)/conventional synthetic disease-modifying antirheumatic drug (csDMARD)-IR patients with RA allocated to TCZ (intravenous or subcutaneous, monotherapy + combination therapy) in phase 3 and 4 studies. End points were change from baseline to week 24 in Clinical Disease Activity Index (CDAI) and quality of life (Health Assessment Questionnaire-Disability Index [HAQ-DI]) and week 24 ACR50 and CDA remission ( $\leq 2.8)$. Using a combination of clinically informed and mathematically driven variable selection techniques, models (with study included as a random effect to account for intracorrelation of observations within each study) were built to optimize fit and explain outcome variance. Analysis of covariance and logistic regression were used for CDAl/HAQ-DI change from baseline and for ACR50/CDAI remission, respectively.

Results: The analyses were performed on 5462 patients from 12 studies. Analysis of baseline characteristics (before TCZ administration) revealed that patients with longer disease duration had been exposed to more CSDMARDS and had worse HAQ-DI than patients with shorter disease duration. Statistical modeling of clinical outcomes showed that disease duration accounted for $<2 \%$ of the variation in HAQ-DI and CDAl change from baseline. Baseline CDAl explained $32 \%$ of the variation in CDAl change from baseline. Patients with higher baseline CDAI values tended to have greater improvements, likely due to having more "room" for improvement and to a higher risk for regression to the mean resulting from the fact that inclusion criteria for most trials required defined thresholds of disease activity, including joint counts. Baseline HAQ-DI, neither an inclusion criterion itself nor influenced by other inclusion criteria, explained $15 \%$ of the variation in HAQ$\mathrm{DI}$ change from baseline. The odds of achieving ACR50 decreased by $9.2 \%$ if disease duration was doubled. The odds of achieving CDAl remission decreased by $15 \%$ per 5 additional years of disease duration and decreased by $22 \%$ per 10 additional score units of CDAl at baseline.

Conclusion: In this pooled analysis of TCZ-treated RA patients, disease duration explained statistically significant but practically small variations in clinical outcomes. These findings indicate that TCZ treatment outcomes are not heavily influenced by disease duration or other baseline characteristics. Disclosure of Interests: Andrea Rubbert-Roth Consultant for: Chugai, El Lilly, Roche, and Sanofi, Speakers bureau: AbbVie, Bristol-Myers Squibb, Chugai, Hexal/Novartis, Janssen, Eli Lilly, Merck Sharp \& Dohme, Pfizer, Roche, and Sanofi, Daniel Aletaha Grant/research support from: AbbVie, Bristol-Myers Squibb, and MSD, Consultant for: AbbVie, Bristol-Myers Squibb, Eli Lilly, Janssen, Medac, Merck, MSD, Pfizer Inc, Roche, and UCB, Speakers bureau: AbbVie, Bristol-Myers Squibb, Eli Lilly, Janssen, Medac, Merck, MSD, Pfizer Inc, Roche, and UCB, Jenny Devenport Employee of: F. Hoffmann-La Roche, Paris N. Sidiropoulos Shareholder of: Roche, Employee of: Genentech, Yves Luder Shareholder of: F. Hoffmann-La Roche, Employee of: F. Hoffmann-La Roche, Michael Edwardes Consultant for: Roche, Johannes W. G. Jacobs Grant/research support from: Roche, Consultant for: Roche DOI: 10.1136/annrheumdis-2019-eular.1144

\section{AB0278 DISCRIMINANT VALIDITY OF THE HANDGRIP STRENGTH TEST IN PATIENTS WITH RHEUMATOID ARTHRITIS: A COHORT STUDY}

Fausto Salaffi ${ }^{1}$, Sonia Farah ${ }^{1}$, Marco DI Carlo ${ }^{1}$, Giacomo Beci ${ }^{1}$, Marina Carotti ${ }^{2}$. ${ }^{1}$ Hospital "Carlo Urbani", Dipartimento scienze cliniche e molecolari, Jesi, Italy; ${ }^{2}$ Ospedali Riuniti Torrette Di Ancona, Dipartimento Radiologia, Torrette, Ancona, Italy

Background: Hand involvement is one of the major determinants of disease outcome affecting the ability to perform activities of daily living and other functional activities in rheumatoid arthritis (RA). Handgrip strength (HS) provides a clinically validated marker of functional disability.

Objectives: The aim of this study was to assess discriminant validity of $\mathrm{HS}$ and to compare it with the Quick Disabilities of Arm Shoulder and Hand (Quick-DASH) (1), Arthritis Impact Measurement Scales 2 (AIMS-2), Hand Health Assessment Questionnaire (Hand HAQ) and Recent-Onset Arthritis Disability (ROAD) upper extremity index (2).

Methods: In this transversal study, a total of 291 patients with RA responding to the ACR 2010 criteria were evaluated. HS was measured twice for both hands by the use of an electronic grip device. The instrument consists of a cylindrical-shape grip device made of 5 force sensors connected to a microcontroller. The correlations between indices were studied through the Pearson's correlation coefficient (r). The discriminatory ability of HS [cut-off values, male $\leq 27 \mathrm{Kg}$, female $\leq 16 \mathrm{Kg}$ ], QuickDASH [range 0-100], AIMS-2 hand/finger function [range 0-10], Hand HAQ [range 0-21], and ROAD upper extremity function [range 0-10] were assessed using receiver operating characteristic (ROC) curves analysis. The external anchor was the general question on Patient Acceptable Symptom State (PASS) (3).

Results: The 239 female and 52 male patients (sex ratio: 4.5F/1M) were of a mean age of $56.5 \pm 12.3$ years $(20-81)$ and a disease duration of 